\title{
Bilateral deep brain stimulation of the subthalamic nucleus in primary Meige syndrome
}

\author{
*Shikun Zhan, MD, Fafa Sun, MD, Yixin Pan, MD, Wei Liu, MD, Peng Huang, MD, \\ Chunyan Cao, PhD, Jing Zhang, MD, Dianyou Li, MD, and Bomin Sun, MD \\ Department of Functional Neurosurgery, Ruijin Hospital, Shanghai Jiao Tong University School of Medicine, Shanghai, China
}

\begin{abstract}
OBJECTIVE Subthalamic nucleus deep brain stimulation has been shown to be effective in reducing symptoms of primary Meige syndrome. However, assessments of its efficacy and safety have been limited to several case reports and small studies.
\end{abstract}

METHODS The authors performed a retrospective study to assess the efficacy and safety of bilateral subthalamic nucleus stimulation in 15 patients with primary Meige syndrome who responded poorly to medical treatments or botulinum toxin injections. Using the movement and disability subscores of the Burke-Fahn-Marsden Dystonia Rating Scale, the authors evaluated the severity of patients' dystonia and related before surgery and at final follow-up during neurostimulation. The movement scale was assessed based on preoperative and postoperative video documentation by an independent rater who was unaware of each patient's neurostimulation status. Quality of life was assessed with the Medical Outcomes Study 36-Item Short-Form General Health Survey.

RESULTS The dystonia movement subscores in 14 consecutive patients improved from $19.3 \pm 7.6$ (mean \pm standard deviation) before surgery to $5.5 \pm 4.5$ at final follow-up ( $28.5 \pm 16.5$ months), with a mean improvement of $74 \%$ ( $p<$ $0.05)$. The disability subscore improved from $15.6 \pm 4.9$ before surgery to $6.1 \pm 3.5$ at final follow-up $(p<0.05)$. In addition, the postoperative SF-36 scores increased markedly over those at baseline. The authors also found that bilateral stimulation of the subthalamic nucleus immediately improved patient symptoms after stimulation and required lower stimulation parameters than those needed for pallidal deep brain stimulation for primary Meige syndrome. Four adverse events occurred in 3 patients; all of these events resolved without permanent sequelae.

CONCLUSIONS These findings provide further evidence to support the long-term efficacy and safety of subthalamic nucleus stimulation as an alternative treatment for patients with medically intractable Meige syndrome.

https://thejns.org/doi/abs/10.3171/2016.12.JNS16383

KEY WORDS dystonia; Meige syndrome; subthalamic nucleus; deep brain stimulation; surgical technique; functional neurosurgery

$\mathrm{M}$ EIGE syndrome is a segmental and adult-onset dystonia characterized by blepharospasm and orofacial-cervical dystonia. It occurs more frequently in women than in men., ${ }^{9,13,33}$ Blepharospasm is the initial complaint of most patients, and dystonic movement patterns can spread to other somatotopic regions over time. Before blepharospasm, the majority of patients complain of ocular symptoms such as photophobia and dry eyes. ${ }^{11,13,38}$

Despite the availability of selective chemical denervation (induced by botulinum toxin injections) and system- atic drug treatments, the disease responds poorly to these therapies and causes substantial motor impairment and social inhibition for some patients. ${ }^{1,11,12}$ Deep brain stimulation (DBS) is a minimally invasive procedure that results in low morbidity, and it has been recognized worldwide for the treatment of primary generalized or other forms of dystonia. ${ }^{18,34,35}$ Pallidal DBS has been shown to provide beneficial effects for alleviating the symptoms of Meige syndrome. , $6,22,23,26-28,31$ The subthalamic nucleus (STN) is a promising alternative target for treating dystonia, especially in those patients who have undergone pallidotomy.,10,21

ABBREVIATIONS BFMDRS = Burke-Fahn-Marsden Dystonia Rating Scale; DBS = deep brain stimulation; GPi = globus pallidus internus; IPG = implantable pulse generator; SF-36 = 36-Item Short-Form General Health Survey; STN = subthalamic nucleus.

SUBMITTED February 16, 2016. ACCEPTED December 5, 2016.

INCLUDE WHEN CITING Published online May 26, 2017; DOI: 10.3171/2016.12.JNS16383.

* Drs. Zhan and F. Sun contributed equally to this work. 
DBS of the STN has been demonstrated to be effective and safe for primary or tardive dystonia and to confer some advantages over pallidal DBS. ${ }^{5,16,25,29,32}$ Although a beneficial effect of bilateral STN DBS in patients with Meige syndrome has been reported, available data on its efficacy and safety are limited. ${ }^{19,24,36}$

Therefore, the aims of our study were to evaluate the effects of chronic stimulation of the bilateral STN on motor symptoms, disability, and health-related quality of life and to describe the adverse events that occurred throughout our follow-up period.

\section{Methods \\ Patient Population}

In our study, 15 patients who had undergone bilateral STN DBS were recruited from Shanghai Ruijin Hospital between 2010 and 2014. All of the patients demonstrated the symptoms of blepharospasm and oromandibular dystonia. Thirteen patients had dystonia that began in their eyelids. For the others, it began in the lower region of the face; the dystonia had spread to the neck in 12 patients, but it was not the dominant problem.

Dystonia was diagnosed by movement disorder neurologists when clinical criteria for idiopathic Meige syndrome were fulfilled. ${ }^{9}$ The consecutive patients whose follow-up time was more than 1 year were included. In addition, the severity of the disease and daily quality of life were evaluated using standardized scales. Patients in our study did not experience satisfactory responses to sufficient medical therapy, including anticholinergics, benzodiazepines, and muscle relaxants, which had been applied earlier. Eight patients in our study had received local botulinum toxin injections regularly, but no sustained improvements in their symptoms were achieved. The remaining 7 patients had received 2-3 local injections without any satisfactory remission, and intolerable adverse effects occurred in some of them, so they refused more injections. Except for dystonia, all of them performed normally in their neurological and psychiatric examinations. In addition, brain MRI revealed no structural causes for their Meige syndrome. Moreover, none of the patients had received any neuroleptic treatment. All of them agreed to participate by providing written informed consent before surgery.

\section{Surgical Procedure and Programming}

The surgical procedures used for STN stimulation were similar to those used to treat patients with Parkinson disease, as described previously. ${ }^{32}$ Briefly, a Leksell stereotactic frame (Elekta, Inc.) was mounted on each patient's head after the induction of local anesthesia, followed by a high-resolution volumetric MRI (1.5 T; General Electric) scanning. The coordinates of the target and the entrance trajectory were determined by visualizing the STN on stereotactic MR images. Intraoperative macrostimulation to test for efficacy and adverse effects was used to confirm the accuracy of the target. After the induction of local anesthesia, quadripolar DBS electrodes (Medtronic model 3387) were implanted into the bilateral STN (Fig. 1). After 3-5 days, when clinical improvements of motor symptoms

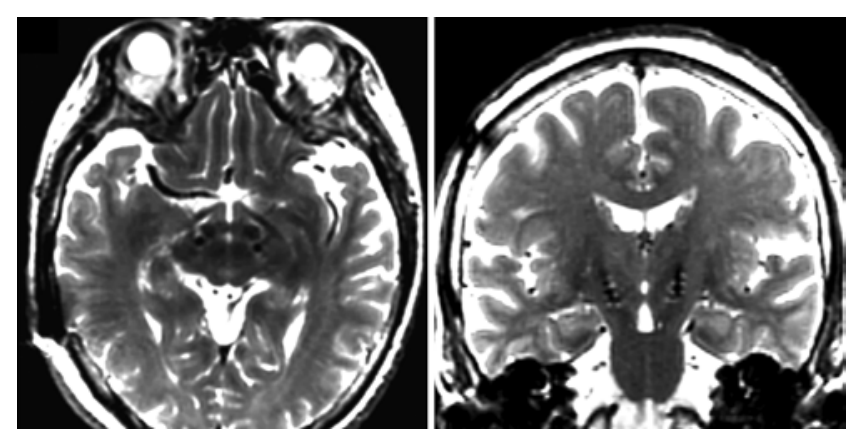

FIG. 1. Localization of therapeutic DBS electrode contacts. Postoperative MR images showing the quadripolar electrodes implanted in the STN of a patient. Left: Axial view. Right: Coronal view.

and no severe complications were observed, implantable pulse generators (IPGs) (Kinetra 7428; Medtronic) were implanted subclavicularly with the patient under general anesthesia. We used postoperative MRI or CT to localize electrode placement within the STN and exclude intracranial hemorrhage.

IPG programming was initiated on the following day. According to postoperative MRI, each electrode contact within the STN was tested separately in a unipolar way for both hemispheres. Symptomatic changes and stimulation-induced adverse effects were recorded. The electrode contacts within the dorsal STN were chosen to be the active contacts because of better symptomatic improvements in and acceptance by the patients. The stimulation parameters were adjusted progressively according to each patient's responses to stimulation and requirements at outpatient follow-up visits.

\section{Data Acquisition}

Each patient was videotaped at baseline and at followup after surgery (Videos 1-4).

VIDEO 1. Before surgery: clip showing a patient who has had Meige syndrome for 2 years. Her eyes are excessively closed. Her orofacial and neck muscles have been contracting abnormally, with her jaw opening and closing involuntarily and her neck forcefully turning to the right. The functions of speaking and chewing have deteriorated significantly. Copyright Bomin Sun. Published with permission. Click here to view.

VIDEO 2. Day of surgery with continual macrostimulation: the patient returns to an almost normal status except for occasionally blinking. Copyright Bomin Sun. Published with permission. Click here to view.

VIDEO 3. Three years after surgery, when the batteries were drained: clip showing that with the battery becoming depleted, her symptoms, such as frequent blinking with prolonged spasms of eyelid closure, grimacing, and continuous lip licking, were worsening. In addition, her neck repetitively leaned to the right. However, the severity of her dystonia did not return to the level it was at before surgery. Copyright Bomin Sun. Published with permission. Click here to view.

VIDEO 4. One day after the batteries were replaced: clip showing symptomatic improvement immediately after the new IPGs were implanted and turned on. The patient is walking naturally without any obviously dystonic movements. Copyright Bomin Sun. Published with permission. Click here to view. 
TABLE 1. Effects of bilateral STN stimulation on BFMDRS movement scores and subitems at baseline and final follow-up visit (12-52 months) in 14 patients

\begin{tabular}{lrrr}
\hline & \multicolumn{2}{c}{ Score (mean \pm SD) } & \\
\cline { 2 - 3 } \multicolumn{1}{c}{ Movement Scale } & $\begin{array}{c}\text { Before } \\
\text { Surgery }\end{array}$ & $\begin{array}{c}\text { After } \\
\text { Surgery }\end{array}$ & $\begin{array}{c}\text { Improvement } \\
(\%)\end{array}$ \\
\hline Eye (0-8) & $5.6 \pm 1.4$ & $1.7 \pm 1.3$ & 71 \\
\hline Mouth (0-8) & $5.8 \pm 1.7$ & $1.5 \pm 0.9$ & 75 \\
\hline Speech and swallowing (0-16) & $4.3 \pm 3.4$ & $1.1 \pm 1.5$ & 73 \\
\hline Neck (0-8) & $3.5 \pm 2.4$ & $1.2 \pm 1.3$ & 64 \\
\hline Total score (0-40) & $19.3 \pm 7.6$ & $5.5 \pm 4.5$ & 74 \\
\hline
\end{tabular}

The severity of dystonia in each patient was evaluated by an independent movement disorder neurologist (J.Z.) who was not involved in the surgery or IPG programming. The patients' symptoms were scored using the movement and disability subscores of the Burke-Fahn-Marsden Dystonia Rating Scale (BFMDRS) ${ }^{4}$ (scores 0-120 and 0-30, respectively, with higher scores indicating greater impairment), and their health-related quality of life was assessed with a validated version of the Medical Outcomes Study 36-Item Short-Form General Health Survey (SF-36), ${ }^{37}$ which assessed 8 aspects of the health status of each patient; scores on each scale can range from 0 (worst) to 100 (best), with higher scores indicating better daily function and condition.

\section{Statistical Analysis}

Scores on the movement and disability subscales of the BFMDRS before surgery and at final follow-up were our primary outcome measures. The secondary outcome measures were quality of life (as reflected by the SF-36 scores), the use of other medical treatments, stimulation parameters, and adverse events.

Data at baseline and at the last follow-up visit were analyzed by using the paired t-test if the data were distributed normally. If not, the Wilcoxon signed-rank test for matched pairs was performed. Correlations between the final improvement in the movement subscores and the relevant variables were analyzed by using Spearman correlation (for quantitative variables) or the Wilcoxon test (for categorical variables). All data are shown as means \pm SD. A probability level of $p<0.05$ was considered statistically significant. All procedures were performed with SPSS 18.0 (SPSS, Inc.).

\section{Results}

\section{Patient Characteristics}

Fourteen consecutive patients met the inclusion criteria of our study and completed the entire follow-up plan. The mean \pm age of the patients at surgery was $53 \pm 8.2$ years (range 39-65 years). The mean disease duration was $4.1 \pm$ 2.7 years (range 1-11 years). However, the clinical manifestation of the disease at onset might have be so mild that most patients and their families were unware of its presence. Grandas et al. ${ }^{11}$ also reported that the mean time between the onset of disease and the appearance of spasms

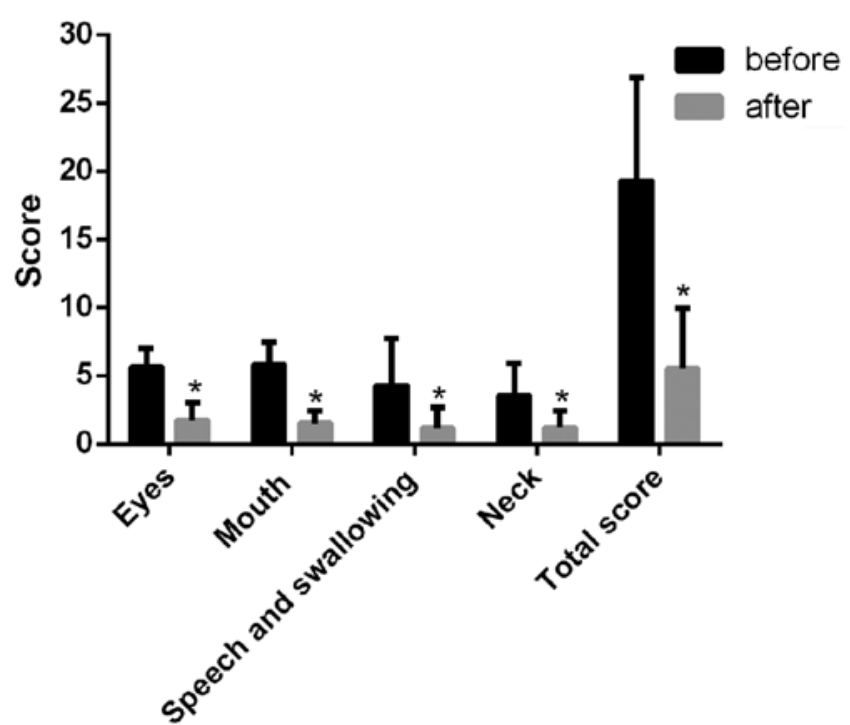

FIG. 2. BFMDRS movement scores and subitems at baseline and last follow-up $(n=14)$. Bars represent mean + SD score. Asterisks indicate comparison with the preoperative score $(p<0.05)$.

was $7.9 \pm 14.5$ years. The mean disease duration observed in our study might have been shorter than what it actually was. The mean follow-up time was $28.5 \pm 16.5$ months (range 12-52 months). Furthermore, 3 of 14 patients received IPG replacements. Mean battery lifetime was 38.7 \pm 8.3 months. One patient was excluded because her left DBS electrode was removed within 1 year.

\section{Outcome Evaluated by BFMDRS Scores}

After chronic stimulation, the BFMDRS movement scores were significantly lower than the preoperative values $(\mathrm{p}=0.001)(5.5 \pm 4.5$ vs $19.3 \pm 7.6$, respectively), with a mean decrease of $74 \%$ at the last follow-up visit. In total, 5 patients experienced an improvement of more than $75 \%$ over their preoperative score. Subitem analysis revealed $71 \%$ improvement in the score for eyes (from 5.6 \pm 1.4 to $1.7 \pm 1.3)(\mathrm{p}<0.001), 75 \%$ improvement for the mouth $(5.8 \pm 1.7$ to $1.5 \pm 0.9)(\mathrm{p}<0.001), 73 \%$ improvement for speech and swallowing $(4.3 \pm 3.4$ to $1.1 \pm 1.5)(\mathrm{p}$ $<0.001)$, and $64 \%$ improvement for the neck $(3.5 \pm 2.4$ to $1.2 \pm 1.3)(\mathrm{p}<0.001)$ over baseline scores (Table 1, Fig. 2). The BFMDRS disability scale scores had also obviously improved after chronic stimulation (Table 2).

\section{Outcome Assessed by SF-36 Scores}

The patients' quality of life was improved significantly. Improvements are reflected by changes in the SF-36 scores after chronic stimulation (Table 3). STN DBS not only decreased the severity of dystonia but also restored the patients' daily function and condition and reduced the negative influence of the disease on their daily life.

\section{Predictors for Movement Improvement}

We assessed correlations between the final BFMDRS movement improvement and baseline factors, as well as duration of stimulation. However, there were no significant 
TABLE 2. Effects of STN stimulation on BFMDRS disability scores and subitems at baseline and last follow-up visit in 14 patients

\begin{tabular}{lcc}
\hline \multirow{2}{*}{ Disability Scale } & \multicolumn{2}{c}{ Score (mean \pm SD) } \\
\cline { 2 - 3 } & Before Surgery & After Surgery \\
\hline Speech (0-4) & $2.8 \pm 0.7$ & $1.2 \pm 0.6$ \\
\hline Writing (0-4) & $1.7 \pm 0.9$ & $0.8 \pm 0.7$ \\
\hline Feeding (0-4) & $2.1 \pm 0.9$ & $0.9 \pm 0.7$ \\
\hline Eating and swallowing (0-4) & $2.4 \pm 0.7$ & $0.9 \pm 0.4$ \\
\hline Hygiene (0-4) & $2.3 \pm 0.8$ & $0.8 \pm 0.7$ \\
\hline Dressing (0-6) & $2.3 \pm 0.8$ & $0.6 \pm 0.5$ \\
\hline Walking (0-4) & $2.1 \pm 1.3$ & $0.9 \pm 0.7$ \\
\hline Total score (0-30) & $15.6 \pm 4.9$ & $6.1 \pm 3.5$ \\
\hline
\end{tabular}

predictors for long-term movement improvement (sex, $\mathrm{p}=$ 0.789; age, $\mathrm{p}=0.642$; duration of disease, $\mathrm{p}=0.903$; duration of stimulation, $\mathrm{p}=0.563$ ).

\section{Stimulation Variables}

Unipolar contact settings with 1 or 2 dorsal contacts as the cathode ( 2 or 3 right electrode contacts or 6 or 7 left electrode contacts) and the IPG case as the anode produced optimal clinical effects. At the last follow-up visit, the stimulation parameters were approximately 135-185 $\mathrm{Hz}, 60-120 \mu \mathrm{sec}$, and 1.95-3.75 V. Most patients had an immediate response when the IPGs were turned on or programmed within a few minutes to a few hours. These effects were sustainably improved over the course of several months to 1 year and then remained stable after several reprogrammings.

\section{Adverse Events}

There were 4 adverse events that occurred in 3 patients. Postoperative MRI revealed asymptomatic intracerebral hemorrhage and transient perioperative edema in 1 patient. A subcutaneous hematoma at the battery site occurred in 1 patient and was resolved by immediate reexploration and hemostasis. Despite conservative management and several debridements, 1 patient had recurrent scalp wound infections and also reported worsening of dystonia at Month 4 after surgery that remained after reprogramming. Postoperative MRI revealed electrode migration on the left side. The patient underwent removal of the electrode and a pallidotomy; therefore, she was excluded from our study.

\section{Discussion}

In the patients with primary Meige syndrome, bilateral chronic stimulation of the STN led to sustained improvement in global motor symptoms and disability over a period of more than 1 year. Subitem analysis also revealed significant improvement in the eyes and mouth and in speech and swallowing, which are the most common Meige syndrome symptoms.

The extent of symptomatic improvements was similar to that previously reported after globus pallidus internus (GPi) DBS for Meige syndrome (ranging from 53\% to
TABLE 3. SF-36 scores before and after surgery in 14 patients

\begin{tabular}{lcc}
\hline \multirow{2}{*}{ Scale } & \multicolumn{2}{c}{ Score (mean \pm SD) } \\
\cline { 2 - 3 } & Before Surgery & After Surgery \\
\hline General health & $21 \pm 7$ & $60 \pm 14$ \\
\hline Physical function & $26 \pm 23$ & $71 \pm 18$ \\
\hline Role-physical & $32 \pm 23$ & $64 \pm 21$ \\
\hline Role-emotional & $40 \pm 23$ & $76 \pm 28$ \\
\hline Social function & $32 \pm 11$ & $75 \pm 12$ \\
\hline Body pain & $56 \pm 23$ & $83 \pm 18$ \\
\hline Vitality & $19 \pm 12$ & $62 \pm 16$ \\
\hline Mental health & $29 \pm 13$ & $65 \pm 16$ \\
\hline
\end{tabular}

$100 \%), 2,6,22,23,26-28,31$ but those results were inferior to our previously published results of STN DBS for primary and tardive dystonia..$^{5,32}$

The strengths of our study are that all motor evaluations were rated by an examiner who was unaware of the patient's preoperative and postoperative statuses; the evaluations were based on standardized videos and validated scales. In addition, the precision of DBS electrode placement was verified by postsurgical MRI or CT. The procedure in each patient followed 2 steps, namely, implantation of the DBS electrode and the IPGs and confirmation of the efficacy and safety for all patients after the patient was satisfied with external stimulator effects. With these advantages, we were able to study long-term treatment response to STN DBS in a relatively large cohort of patients who suffered from primary Meige syndrome.

Another strength of our study was that all the patients had the procedure performed by 1 neurosurgeon (B.S.), and the programming of all IPGs was performed by 1 doctor (D.L.), which excluded possible bias caused by using different neurosurgeons.

The definite mechanisms of DBS for dystonia are unknown. We propose that high-frequency stimulation of the STN results in direct inhibition of STN excitatory output to the GPi and substantia nigra pars reticulate to modulate the imbalance within the basal ganglia-thalamus-cortical circuit. ${ }^{8,20}$ Moreover, neuroimaging and neurophysiological studies have revealed the hyperactivities of the motor circuit. ${ }^{30,39}$ Cortical or subcortical network plasticity might be another mechanism that explains the effects of DBS on dystonia. ${ }^{15,17}$ The progressive improvement in dystonic symptoms and the latency of recurrence of symptoms after turning off the IPGs provide evidence for this mechanism. In our experience, the best therapeutic electrode contacts are located mostly in the dorsal STN, with its abundance of interconnecting fibers, including pallidothalamic, pallidosubthalamic, and subthalamopallidal fibers. ${ }^{14,20}$ While disrupting the afferent and efferent connectivity with the STN, stimulation of these fibers might produce the most optimal outcome, similar to that of pallidal DBS. In previously published reports and our experiences, there has been no significant difference between GPi and STN DBS for the treatment of dystonia. However, STN DBS is superior in some aspects; improvement of symptoms is found immediately after stimulation and lower stimulation pa- 
rameters are needed, while battery life is longer than with GPi DBS for primary or tardive dystonia. $5,16,21,25,29,32$ Furthermore, there are already some reports on the effects of STN DBS for Meige syndrome..$^{19,24,36}$ Thus, we proposed the hypothesis that bilateral stimulation of the STN would produce positive effects on the symptoms of patients with Meige syndrome. The GPi might be an optional target for the treatment of Meige syndrome, and further research with the GPi versus the STN as the target is recommended.

Prompt symptomatic improvements were observed in the majority of patients in our study after electrode placement because of the microlesion effects. In addition, most patients had an immediate response to stimulation after programming, which enabled us to select the most optimally individual stimulation parameters quickly, which was economical and saved time for the patients.

Whether disease duration or age at surgery is an independent predictor associated with the movement outcome in patients with dystonia is controversial. ${ }^{3}$ However, in accordance with previous studies, ${ }^{34,36}$ no baseline factors that we assessed (sex, age, or duration of disease) were significant predictors of long-term movement improvement in our study.

STN DBS was safe in patients with Meige syndrome. In our study, there were 4 adverse events, and all of them resolved without permanent sequelae. Stimulation-induced bradykinesia was not observed in our patients. In addition, the mean dose of medications, taken before surgery, decreased gradually in all patients after surgery. At the last follow-up visit, none of the patients needed further botulinum toxin injection treatment. However, these findings are preliminary and are limited to our patient selection and sample size. Large controlled multicenter doubleblinded studies are needed to provide further evidence for the efficacy and safety of STN DBS in patients with Meige syndrome.

\section{Conclusions}

Our study shows that bilateral stimulation of the dorsal STN results in a sustained decrease in the severity of dystonia and an improvement of functional disability and patient quality of life without severe complications. In addition, the STN, as an alternative to the GPi, will be a novel target for DBS for treating refractory Meige syndrome.

\section{Acknowledgments}

This study was funded by the National Natural Science Foundation of China (Grant No. 81271518).

\section{References}

1. Bhidayasiri R, Cardoso F, Truong DD: Botulinum toxin in blepharospasm and oromandibular dystonia: comparing different botulinum toxin preparations. Eur J Neurol 13 (Suppl 1):21-29, 2006

2. Blomstedt P, Tisch S, Hariz MI: Pallidal deep brain stimulation in the treatment of Meige syndrome. Acta Neurol Scand 118:198-202, 2008

3. Bronte-Stewart H, Taira T, Valldeoriola F, Merello M, Marks WJ Jr, Albanese A, et al: Inclusion and exclusion criteria for DBS in dystonia. Mov Disord 26 (1 Suppl 1):S5-S16, 2011
4. Burke RE, Fahn S, Marsden CD, Bressman SB, Moskowitz C, Friedman J: Validity and reliability of a rating scale for the primary torsion dystonias. Neurology 35:73-77, 1985

5. Cao C, Pan Y, Li D, Zhan S, Zhang J, Sun B: Subthalamus deep brain stimulation for primary dystonia patients: a longterm follow-up study. Mov Disord 28:1877-1882, 2013

6. Capelle HH, Weigel R, Krauss JK: Bilateral pallidal stimulation for blepharospasm-oromandibular dystonia (Meige syndrome). Neurology 60:2017-2018, 2003

7. Dec M, Tutaj M, Rudzińska M, Szczudlik A, Koziara H, Bonicki W, et al: Subthalamic nucleus deep brain stimulation after bilateral pallidotomy in the treatment of generalized dystonia. Parkinsonism Relat Disord 20:131-133, 2014

8. Dostrovsky JO, Lozano AM: Mechanisms of deep brain stimulation. Mov Disord 17 (3 Suppl 3):S63-S68, 2002

9. Faulstich ME, Carnrike CL Jr, Williamson DA: Blepharospasm and Meige syndrome: a review of diagnostic, aetiological and treatment approaches. J Psychosom Res 29:89-94, 1985

10. Fonoff ET, Campos WK, Mandel M, Alho EJ, Teixeira MJ: Bilateral subthalamic nucleus stimulation for generalized dystonia after bilateral pallidotomy. Mov Disord 27:15591563,2012

11. Grandas F, Elston J, Quinn N, Marsden CD: Blepharospasm: a review of 264 patients. J Neurol Neurosurg Psychiatry 51:767-772, 1988

12. Jankovic J: Treatment of dystonia. Lancet Neurol 5:864872,2006

13. Jankovic J, Ford J: Blepharospasm and orofacial-cervical dystonia: clinical and pharmacological findings in 100 patients. Ann Neurol 13:402-411, 1983

14. Katayama Y, Oshima H, Kano T, Kobayashi K, Fukaya C, Yamamoto T: Direct effect of subthalamic nucleus stimulation on levodopa-induced peak-dose dyskinesia in patients with Parkinson's disease. Stereotact Funct Neurosurg 84:176-179, 2006

15. Kim SJ, Udupa K, Ni Z, Moro E, Gunraj C, Mazzella F, et al: Effects of subthalamic nucleus stimulation on motor cortex plasticity in Parkinson disease. Neurology 85:425-432, 2015

16. Kleiner-Fisman G, Liang GS, Moberg PJ, Ruocco AC, Hurtig HI, Baltuch GH, et al: Subthalamic nucleus deep brain stimulation for severe idiopathic dystonia: impact on severity, neuropsychological status, and quality of life. J Neurosurg 107:29-36, 2007

17. Kumar R, Dagher A, Hutchison WD, Lang AE, Lozano AM: Globus pallidus deep brain stimulation for generalized dystonia: clinical and PET investigation. Neurology 53:871-874, 1999

18. Kupsch A, Benecke R, Müller J, Trottenberg T, Schneider GH, Poewe W, et al: Pallidal deep-brain stimulation in primary generalized or segmental dystonia. N Engl J Med 355:1978-1990, 2006

19. Lyons MK, Birch BD, Hillman RA, Boucher OK, Evidente VG: Long-term follow-up of deep brain stimulation for Meige syndrome. Neurosurg Focus 29(2):E5, 2010

20. Moyer JT, Danish SF, Finkel LH: Deep brain stimulation: anatomical, physiological, and computational mechanisms. Network 22:186-207, 2011

21. Novak KE, Nenonene EK, Bernstein LP, Vergenz S, Cozzens JW, Rezak M: Successful bilateral subthalamic nucleus stimulation for segmental dystonia after unilateral pallidotomy. Stereotact Funct Neurosurg 86:80-86, 2008

22. Opherk C, Gruber C, Steude U, Dichgans M, Bötzel K: Successful bilateral pallidal stimulation for Meige syndrome and spasmodic torticollis. Neurology 66:E14, 2006

23. Ostrem JL, Marks WJ Jr, Volz MM, Heath SL, Starr PA: Pallidal deep brain stimulation in patients with cranial-cervical dystonia (Meige syndrome). Mov Disord 22:1885-1891, 2007

24. Ostrem JL, Markun LC, Glass GA, Racine CA, Volz MM, 
Heath SL, et al: Effect of frequency on subthalamic nucleus deep brain stimulation in primary dystonia. Parkinsonism Relat Disord 20:432-438, 2014

25. Pahapill PA, O'Connell B: Long-term follow-up study of chronic deep brain stimulation of the subthalamic nucleus for cervical dystonia. Neuromodulation 13:26-30, 2010

26. Reese R, Gruber D, Schoenecker T, Bäzner H, Blahak C, Capelle HH, et al: Long-term clinical outcome in Meige syndrome treated with internal pallidum deep brain stimulation. Mov Disord 26:691-698, 2011

27. Romito LM, Elia AE, Franzini A, Bugiani O, Albanese A: Low-voltage bilateral pallidal stimulation for severe Meige syndrome in a patient with primary segmental dystonia: case report. Neurosurgery 67 (3 Suppl Operative):onsE308, 2010

28. Sako W, Morigaki R, Mizobuchi Y, Tsuzuki T, Ima H, Ushio Y, et al: Bilateral pallidal deep brain stimulation in primary Meige syndrome. Parkinsonism Relat Disord 17:123-125, 2011

29. Schjerling L, Hjermind LE, Jespersen B, Madsen FF, Brennum J, Jensen SR, et al: A randomized double-blind crossover trial comparing subthalamic and pallidal deep brain stimulation for dystonia. J Neurosurg 119:1537-1545, 2013

30. Schmidt KE, Linden DE, Goebel R, Zanella FE, Lanfermann H, Zubcov AA: Striatal activation during blepharospasm revealed by fMRI. Neurology 60:1738-1743, 2003

31. Sobstyl M, Ząbek M, Mossakowski Z, Zaczyński A: Pallidal deep brain stimulation in the treatment of Meige syndrome. Neurol Neurochir Pol 48:196-199, 2014

32. Sun B, Chen S, Zhan S, Le W, Krahl SE: Subthalamic nucleus stimulation for primary dystonia and tardive dystonia. Acta Neurochir Suppl 97:207-214, 2007

33. Tolosa E, Kulisevsky J, Fahn S: Meige syndrome: primary and secondary forms. Adv Neurol 50:509-515, 1988

34. Vidailhet M, Vercueil L, Houeto JL, Krystkowiak P, Benabid AL, Cornu P, et al: Bilateral deep-brain stimulation of the globus pallidus in primary generalized dystonia. $\mathbf{N}$ Engl J Med 352:459-467, 2005

35. Volkmann J, Wolters A, Kupsch A, Müller J, Kühn AA, Schneider GH, et al: Pallidal deep brain stimulation in patients with primary generalised or segmental dystonia: 5-year follow-up of a randomised trial. Lancet Neurol 11:10291038,2012

36. Wang X, Zhang C, Wang Y, Liu C, Zhao B, Zhang JG, et al: Deep brain stimulation for craniocervical dystonia (Meige syndrome): A report of four patients and a literature-based analysis of its treatment effects. Neuromodulation 19:818 823, 2016

37. Ware JE Jr, Sherbourne CD: The MOS 36-item Short-Form Health Survey (SF-36). I. Conceptual framework and item selection. Med Care 30:473-483, 1992

38. Weiss EM, Hershey T, Karimi M, Racette B, Tabbal SD, Mink JW, et al: Relative risk of spread of symptoms among the focal onset primary dystonias. Mov Disord 21:1175-1181, 2006

39. Yang J, Luo C, Song W, Guo X, Zhao B, Chen X, et al: Diffusion tensor imaging in blepharospasm and blepharospasmoromandibular dystonia. J Neurol 261:1413-1424, 2014

\section{Disclosures}

The authors report no conflict of interest concerning the materials or methods used in this study or the findings specified in this paper.

\section{Author Contributions}

Conception and design: B Sun, Zhan, F Sun, Li. Acquisition of data: Pan, Liu, Zhang. Analysis and interpretation of data: Liu, Cao. Drafting the article: F Sun. Critically revising the article: all authors. Reviewed submitted version of manuscript: B Sun, Zhan, F Sun, Cao, Zhang, Li. Approved the final version of the manuscript on behalf of all authors: B Sun. Statistical analysis: F Sun, Pan, Liu. Administrative/technical/material support: all authors. Study supervision: B Sun, Zhan, Cao, Zhang, Li.

\section{Supplemental Information \\ Videos \\ Video 1. https://vimeo.com/202218461. \\ Video 2. https://vimeo.com/202217771. \\ Video 3. https://vimeo.com/202217794. \\ Video 4. https://vimeo.com/202217813.}

\section{Correspondence}

Bomin Sun, Department of Functional Neurosurgery, Ruijin Hospital, Shanghai Jiao Tong University School of Medicine, 197 Rui Jin Rd., Shanghai 200025, People's Republic of China. email: bomin_sun@163.com. 